Original Research Paper

\title{
Application of Time Series Modeling to Study River Water Quality
}

\author{
${ }^{1}$ Maryam Ghashghaie, ${ }^{2}$ Kaveh Ostad-Ali-Askari, ${ }^{3}$ Saeid Eslamian and ${ }^{4}$ Vijay P. Singh \\ ${ }^{I}$ Department of Water Resources Engineering, \\ Faculty of Agriculture, Bu-Ali Sina University, Hamedan, 6517833131, Iran \\ ${ }^{2}$ Department of Civil Engineering, Isfahan (Khorasgan) Branch, Islamic Azad University, Isfahan, Iran \\ ${ }^{3}$ Department of Water Engineering, Isfahan University of Technology, Isfahan, Iran \\ ${ }^{4}$ Department of Biological and Agricultural Engineering and \\ Zachry Department of Civil Engineering, Texas A and M University, \\ 321 Scoates Hall, 2117 TAMU, College Station, Texas 77843-2117, U.S.A
}

Article history

Received: 19-03-2018

Revised: 20-04-2018

Accepted: 24-04-2018

Corresponding Author:

Kaveh Ostad-Ali-Askari

Department of Civil

Engineering, Isfahan

(Khorasgan) Branch, Islamic

Azad University, Isfahan, Iran

Email: koa.askari@khuisf.ac.ir

\begin{abstract}
Water deficit problem originates from two factors: population increase and water pollution. However, studying and forecasting the quality of water are necessary to avoid serious problems in future through managerial works. In present study, using time series modeling, the quality of Madian Rood River is studied at Baraftab station using time series analysis. Nine parameters of water quality are studied such as: TDS, EC, $\mathrm{HCO}_{3}{ }^{-}, \mathrm{Cl}^{-}, \mathrm{SO}_{4}{ }^{2+}$, $\mathrm{Ca}^{2+}, \mathrm{Mg}^{2+}, \mathrm{Na}^{+}$and $\mathrm{SAR}$. Investigation of observed time series shows that there is a common increasing trend for all parameters unless $\mathrm{Na}^{+}$and SAR. The order of models for each parameter was determined using Auto Correlation Function (ACF) and Partial Auto Correlation Function (PACF) of time series. The ARIMA model was used to generate and forecast the quality of stream flows. Akaike Information Criterion (AIC), Determination Coefficient $\left(\mathrm{R}^{2}\right)$, Root Mean Square Error (RMSE) and (Volume Error in Percent (VE \%) criteria were referred to evaluate the generation and validation results. The Results show that time series modeling is quite capable of water quality forecasting. For the majority of forecasts, the value of $\mathrm{R}^{2}$ was greater than 0.6 between predicted and observed values.
\end{abstract}

Keywords: ARIMA, Time Series, Trend Elimination, Water Quality

\section{Introduction}

Water quality is a main subject of life due to its direct impact on human health. Water quality could be affected by geologic structure, salinity, overdraw of groundwater, urban and domestic wastewater entrance into surface streams as well as agricultural drainage and a wide range of chemical compounds (Tsakiris and Alexakis, 2012).

Different methods and approaches are used to investigate and forecast the quality of water. Also the majority of water software such as SWAT, QUAL2K and MIKE-11 benefit from especial tools to assess the quality of streams. Time series analysis is one of the useful methods which are applied in water quality modeling and forecasting.

Time series analyses is useful in understanding and analyzing the process of different phenomena. It is also helpful in generating past observations forecasting the future values based on the past memory.
Time series is composed of a string of data over time with an equal interval between all data. The interval can be defined as daily, weekly, monthly as well as yearly time steps. Time series analyzing is used in decision making in many hydrological processes and operation systems. Time series analysis in hydrology has two main goals:

1. Understand and model the stochastic mechanism of a hydrologic process and

2. Forecast the future values for the process

\section{Applied Time-Series Analysis}

Main statistical characteristics of a hydrologic time series could be reproduced using ARIMA (autoregressive, integrated, moving average) models. ARIMA models have been used to examine runoff and river discharge (Kurunç et al., 2005;), water levels of lakes (Sheng and Chen 2011, Ghashghaie and Nozari, 2018), sediment yield 
(Hanh et al., 2010) and water quality (Ahmad et al., 2001, Lehmann and Rode, 2001; Faruk, 2010; Hanh et al., 2010; Durdu, 2010; Khalil Arya and Zhang, 2015).

Auto correlated models were used in some studies on stream analyzing (Thomas and Fiering, 1962). McKerchar and Delleur (1974) established the main step to apply time series in hydrology using Autoregressive Integrated Moving Average. They used seasonal modeling as well to analyze seasonal characteristics of stream parameters. Time series modeling is efficient in identifying and forecasting monthly stream pattern and integrated water resources management (Jalal Kamali, 2002). It has been widely used to forecast hydrologic variables such as rainfall and discharge as well as flood (Komornık et al., 2006; Damle and Yalcin, 2007).

Many studies have focused on water quality parameters, a Brief reviews of which are mentioned as follow.

\section{Applied Time Series Analysis on Surface Water Quality}

Hirsch et al. (1982) used new methods to analyze monthly water quality data for monotonic trends. Also temporal changes in water quality parameters such as $\mathrm{pH}$, Alkalinity, total Phosphorous and Nitrate concentrations have been studied using data series of Niagara (El-Shaarawi et al., 1983). Yu et al. (1993) analyzed surface water quality data of the Arkansas, Verdigris and Neosho as well as Walnut river basin to study trends in 17 major constituents using 4 different nonparametric methods.

The trend of upland stream and water quality data from Plynlimon, mid wales were examined (Robson and Neal, 1996) applying the seasonal Kendall test. studied the time series of water quality parameters and the discharge of Strymon River in Greece from 1980 to 1997. Gangyan et al. (2002) investigated the temporal sediment load characteristics of the Yangtze River using the turning point test, Kendall's rank correlation test. Jassby et al. (2003) developed a time series model for Secchi depth in Lake Tahoe, USA. Panda et al. (2011) studied the trends in sediment load of a tropical river basin in India.

\section{Applied Time Series Analysis on Groundwater Quality}

Time series analysis has been applied on the groundwater quality modeling in different regions. Chang (1988) developed a modeling technique including the homogeneity test of data and the best model selection to fit the water loss series using a stochastic process.

Wilson et al. (1992) determined groundwater quality changes as a result of anthropogenic activities using a time series analysis of well water quality data from 1964 to 1965. Loftis (1996) reviewed national assessments of agricultural and urban, point source and hazardous waste studies on regional and localized groundwater quality all over the world including a few snapshots. Lee and Lee (2003) evaluated and quantified the potential of natural reduction of groundwater in an industrial area of Seoul, Korea. Different studies have focused on water temperature time series () Kim et al. (2005) applied time series analysis in a study through which the effect of tide on groundwater quality in a coastal area of Korea was investigated. Also temporal variability of turbidity, dissolved oxygen, conductivity, temperature and fluorescence in the lower Mekong River as investigated using time series analysis (Irvine et al., 2011).Water quality modeling plays an important role in water quality management and conservation (Singh et al., 2004; Chenini and Khemiri 2009; Fang et al., 2010; Su et al., 2011;; Prasad et al., 2014; Seth et al., 2013;Parmar and Bhardwaj, 2014).

Application of time series analyzing in water resources demonstrates the efficiency and capability of this approach since it considers stochastic nature of hydrological processes. This study aims to use this methodology in water quality analyzing.

In present study, water quality parameters of Madian Rood are investigated at Baraftab station. The methodology and the study area are presented at the following section.

\section{Materials and Methods}

\section{The Study Area}

The study area is located in the west of Iran in Kuhdasht region. Figure 1 shows the study area in Iran. This station of the river is located at $47^{\circ} 48^{\prime} \mathrm{E}$ and $33^{\circ} 18^{\prime} \mathrm{N}$. The area of basin is about $1108 \mathrm{Km}^{2}$ which is located at Kashkan basin of Karkheh watershed.

Time series of 9 water quality parameters such as TDS, EC, $\mathrm{HCO}_{3}^{-}, \mathrm{Cl}^{-}, \mathrm{SO}_{4}{ }^{2-}, \mathrm{Ca}^{2+}, \mathrm{Mg}^{2+}, \mathrm{Na}^{+}$and $\mathrm{SAR}$ of Baraftab station at Madian Rood River were studied in this research.

\section{Methodology}

The theory and application of the ARIMA modeling have been conducted in different studies (Pankratz, 1983; Vandaele, 1983; Box and Jenkins, 1976). The background of this methodology is presented briefly. Autoregressive (AR) models estimate the values for the dependent variable, $Z_{t}$, as regression function of previous values, $Z_{t-1}, Z_{t-2} \ldots Z_{\mathrm{t}-\mathrm{n}}$. An AR model of order 1 (i.e. an AR (1) model) is defined as Equation 1:

$Z_{t}=\Phi_{1} Z_{t-1}+\alpha_{t}(1)$

where, $Z_{t}$ and $Z_{t-1}$ show deviations from the mean, $\Phi_{1}$ is the first-order AR coefficient and describes the effect of a unit change in $Z_{t-1}$ on $Z_{t}$ and $\alpha_{t}$ is the white noise. 


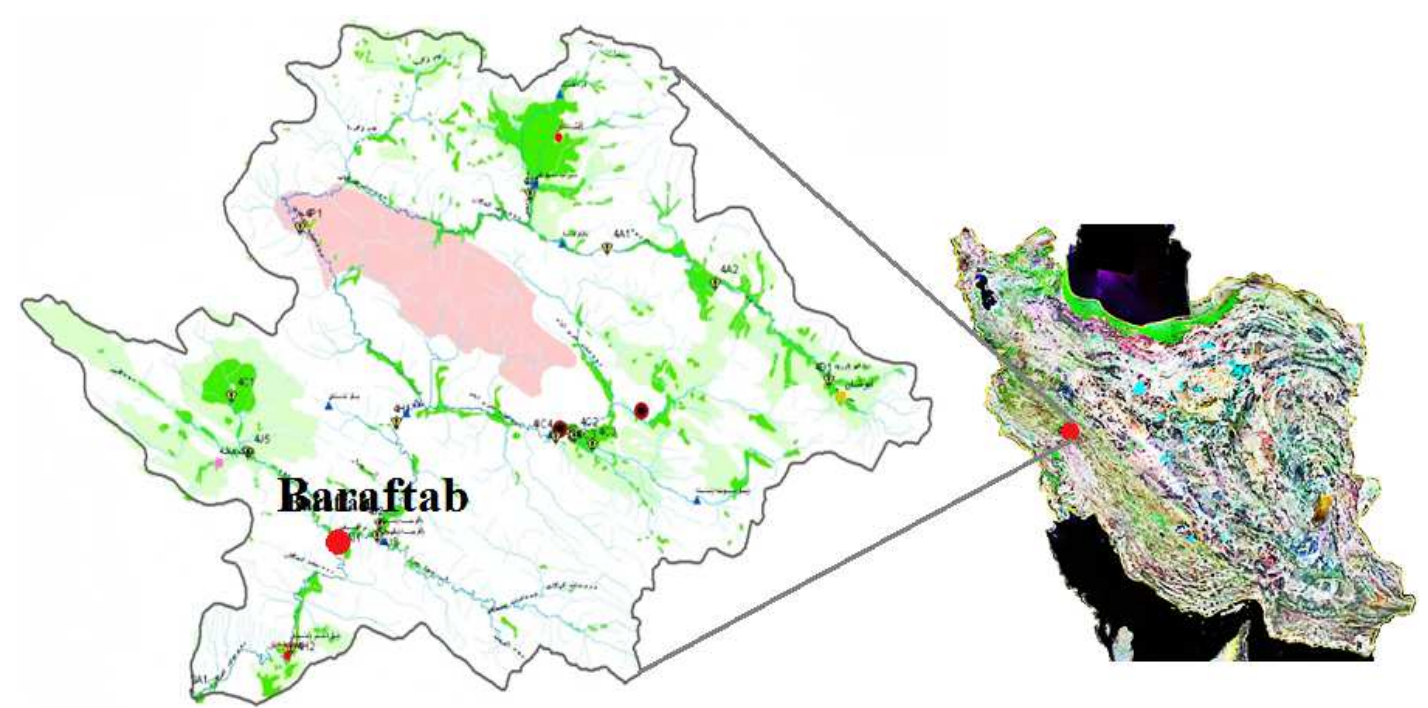

Fig. 1: The location of the study area

The $\alpha_{t}$ values are assumed normally distributed and independent with the mean value of 0 and a constant value of variance. The value of variance for a stationarity model of $Z_{t}$ is positive and finite (Vandaele, 1983) and $\left|\Phi_{1}\right|$ must be less than 1 to meet these conditions. The Higher order of AR models are possible, similar to a multiple regression; for this case, the absolute value of each AR coefficient should be less than 1 .

Moving Average (MA) models incorporate the past random fluctuations to show the time series. An MA model of order 1 (i.e., an MA (1) model) can be expressed as Equation 2:

$$
Z_{t}=\alpha_{t}-\theta_{1} \alpha_{t-1}
$$

where, $\theta_{1}$ is the MA coefficient and the random shocks (white noise) $\left(\alpha_{t}\right)$ are assumed normally distributed and independent with the mean value of 0 and a constant value of variance. The value of $\left|\theta_{1}\right|$ must be less than 1. The Values greater than 1 show that the observations further in the past have a greater effecton $Z_{t}$ than more recent observations which is not plausible in a hydrologic time series. Higher order of the MA models is possible. Similar to the AR model coefficients, the absolute value of each MA coefficient should be less than 1. Since the parsimony is important in a time series modeling it sometimes could be met using a mixed (ARMA) model instead of a pure AR or MA model. Also representing a time series with an ARMA $(1,1)$ model is more parsimonious in comparison with an AR (3) model because the model requires fewer parameter estimation. Mixing models is possible because they could be theoretically denoted as pure AR or MA models of infinite order (Vandaele, 1983). A mixed model can supply more flexibility to describe the results of interaction between the processes (Salas et al., 1980).

The main goal of a time series analysis is to understand seasonal patterns and/or trends over time. Most of the time hydrologic time series show a regular seasonal pattern which can be removed by standardizing the data for the seasonal mean and standard.

Also understanding and modeling the correlational structure in the time series is another goal of time series analysis. The basic stages in the ARIMA modeling are composed of: (1) Identifying the model, (2) estimating the orders of the model and (3) verifying the model using the standard tests. The results are presented in the following section.

\section{Results and Discussion}

In this study, nine water quality parameters were studied. Using one lag the data were transformed to make a yearly stationary time series. At the second stage MINITAB 14 was used in this study to analyze these 9 time series. The ACF and PACF of time series were plotted at the second stage.

After identifying the ACF and PACF of each time series the order of model was determined at first. Then 4 criteria were used to compare the results of series generation through the suggested models and 35 datatime series were generated. Based on 4 criteria, the best model was selected for each time series of 35 data and these models were used to forecast 5 values of time series. These 4 criteria were $\mathrm{R}^{2}$, AIC, RMSE and VE \% (Karamouz and Araghinejad, 2005). The value of AIC is estimated through Equation 3:

$$
A I C=\left(n \times \operatorname{Ln}\left(\sigma^{2}\right)+2 \times(p+q)\right)
$$


where, $\sigma$ is the standard error of residuals; $n$ is the sample size; $p$ and $p$ show the order of AR and MA respectively. Also the value of VE \% is calculated using (Equation 4):

$V E \%=\frac{\sum_{t=1}^{n}\left|\frac{y_{t}-\hat{y}_{t}}{y_{t}}\right|}{n}$

where, $y_{t}$ and $\hat{y}_{t}$ show the observed and estimated values respectively and $\mathrm{n}$ is the sample size.

At the next stage forecasting the water quality parameters was accomplished. Results are shown in the following figs. Previously mentioned criteria (AIC, RMSE and VE \%) were used at this stage for demonstrating the capability of each model to forecast the value of data.

Figure 2 shows the standardized time series of water quality data for TDS parameter and the forecasted values of 5 successive years.

Standard series of TDS show that this parameter has a positive trend, which was removed and modeled as it is demonstrated in Table 1.

The Results show that the model is capable of modeling the time series well. However, there is an increasing trend for the observed values of 5 successive years which is not the same for forecasted one.

For the second parameters, as it is clear from Fig. 3, EC time series follows an increasing trend which was removed at the second stage. Then using the best model, it was forecasted for 5 years.

Also Table 2 shows the results for modeling and choosing the best fit.

Figure 4 shows $\mathrm{HCO}_{3}{ }^{-}$time series and forecasted series for 5 years. The forecasted values for 5 successive years are shown in this Figure as well.

Similar to the previous parameters $\mathrm{HCO}_{3}{ }^{-}$follows an increasing slope and, the modeling was accomplished after trend elimination. Table 3 shows the results of modeling for this parameter.

Standardized time series of $\mathrm{Cl}^{-}$is presented in Fig. 5. Also the forecasted values of this parameter are shown in this Figure.

The results show that the selected model, shown in Table 4, is capable of modeling the series well.

Figure 6 demonstrates the standard series of $\mathrm{SO}_{4}{ }^{2-}$. Modeling the $\mathrm{SO}_{4}{ }^{2-}$ series was done on the original series without trend elimination. The forecasted values for 5 years are shown in this Figure too.

The results of generation and the best fit are shown in Table 5.

Also the standard series of $\mathrm{Ca}^{2+}$ is presented in Fig. 7 and the forecasted values of this parameter are shown in this Figure.

The results presented in Table 6 show that the selected model, shown in Table 6, is capable of modeling the series well.
Fig. 8 demonstrates the standard series of $\mathrm{Mg}^{2+}$. The Fig. 8 shows that the series follow an increasing trend. Modeling the $\mathrm{Mg}^{2+}$ series was done after trend elimination which is presented in this Figure as well.

Table 7 shows that the selected model is capable of modeling the series well.

Table 1: The results of TDS generation, order $(1,3)$

\begin{tabular}{llllll}
\hline MODEL & R & $\mathrm{R}^{2}$ & AIC & RMSE & VE \% \\
\hline$(1,1,2)$ & 0.81 & 0.66 & -93.05 & 0.04 & 1.13 \\
$(1,1,3)$ & 0.86 & 0.74 & -98.83 & 0.03 & 1.02 \\
$(2,1,3)$ & 0.86 & 0.74 & -96.95 & 0.03 & 1.00
\end{tabular}

Table 2: The results of EC generation, order $(1,1)$

\begin{tabular}{llllll}
\hline MODEL & R & $\mathrm{R}^{2}$ & AIC & RMSE & VE \% \\
\hline$(1,1,1)$ & 0.73 & 0.54 & -76.97 & 0.05 & 1.36 \\
$(1,1,2)$ & 0.81 & 0.66 & -89.01 & 0.04 & 1.29 \\
$(2,1,1)$ & 0.83 & 0.68 & -90.36 & 0.04 & 1.25 \\
$(2,1,2)$ & 0.83 & 0.69 & -89.82 & 0.04 & 1.27 \\
$(1,1,3)$ & 0.85 & 0.73 & -94.32 & 0.04 & 1.21 \\
$(2,1,3)$ & 0.86 & 0.73 & -92.51 & 0.04 & 1.18 \\
\hline
\end{tabular}

Table 3: The results of $\mathrm{HCO}_{3}{ }^{-}$generation, order $(1,2)$

\begin{tabular}{llllll}
\hline MODEL & $\mathrm{R}$ & $\mathrm{R}^{2}$ & AIC & RMSE & VE \% \\
\hline$(1,1,2)$ & 0.79 & 0.62 & -43.72 & 0.11 & 2.66 \\
$(2,1,2)$ & 0.77 & 0.59 & -39.39 & 0.12 & 3.74 \\
$(1,1,3)$ & 0.80 & 0.64 & -48.27 & 0.11 & 2.39 \\
$(2,1,3)$ & 0.76 & 0.58 & -39.17 & 0.12 & 4.68 \\
\hline
\end{tabular}

Table 4: The results of $\mathrm{Cl}^{-}$generation,order $(1,2)$

\begin{tabular}{llllll}
\hline MODEL & R & $\mathrm{R}^{2}$ & AIC & RMSE & VE \% \\
\hline$(1,1,1)$ & 0.84 & 0.70 & -81.94 & 0.04 & 0.80 \\
$(1,1,2)$ & 0.84 & 0.70 & -77.96 & 0.04 & 0.80 \\
$(2,1,2)$ & 0.84 & 0.70 & -76.12 & 0.04 & 0.79 \\
$(1,1,3)$ & 0.84 & 0.70 & -75.97 & 0.04 & 0.80 \\
$(2,1,1)$ & 0.82 & 0.67 & -74.52 & 0.05 & 0.90 \\
\hline
\end{tabular}

Table 5: The results of $\mathrm{SO}_{4}{ }^{2-}$ generation,order $(1,1)$

\begin{tabular}{llllll}
\hline MODEL & $\mathrm{R}$ & $\mathrm{R}^{2}$ & AIC & RMSE & VE \% \\
\hline$(1,0,1)$ & 0.51 & 0.26 & -27.71 & 0.11 & 1.18 \\
$(1,1,1)$ & 0.46 & 0.21 & -23.09 & 0.11 & 1.42 \\
$(1,1,2)$ & 0.49 & 0.24 & -21.10 & 0.11 & 1.42 \\
$(2,1,1)$ & 0.56 & 0.31 & -20.58 & 0.11 & 1.70 \\
$(2,1,2)$ & 0.60 & 0.36 & -21.25 & 0.11 & 1.67 \\
$(1,1,3)$ & 0.55 & 0.30 & -22.47 & 0.11 & 1.64 \\
\hline
\end{tabular}

Table 6: The results of $\mathrm{Ca}^{2+}$ generation, order $(1,1)$

\begin{tabular}{llllll}
\hline MODEL & $\mathrm{R}$ & $\mathrm{R}^{2}$ & AIC & RMSE & VE $\%$ \\
\hline$(1,0,1)$ & 0.77 & 0.59 & -61.39 & 0.06 & 1.32 \\
$(1,0,2)$ & 0.82 & 0.67 & -66.36 & 0.06 & 1.33 \\
$(2,0,1)$ & $\ldots$ & & & & \\
$(2,0,2)$ & $\ldots$ & & & & \\
$(1,1,1)$ & 0.78 & 0.60 & -61.90 & 0.06 & 1.15 \\
$(1,1,2)$ & 0.84 & 0.70 & -69.94 & 0.05 & 1.16 \\
$(2,1,1)$ & 0.87 & 0.76 & -76.41 & 0.05 & 1.23 \\
$(2,1,2)$ & 0.87 & 0.76 & -74.52 & 0.05 & 1.22 \\
\hline
\end{tabular}



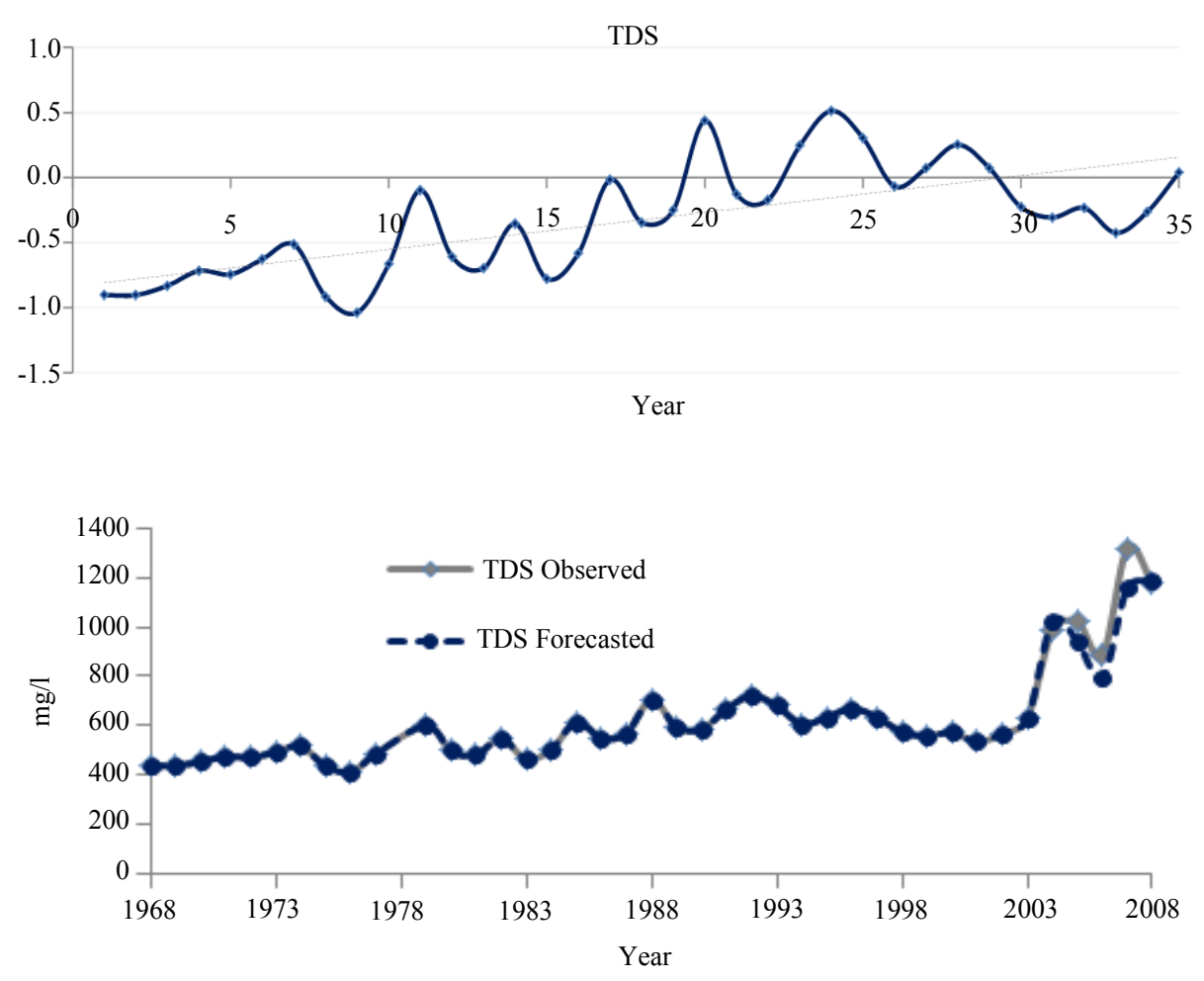

Fig. 2: Standardized time series of TDS and the forecasted values for 5 years
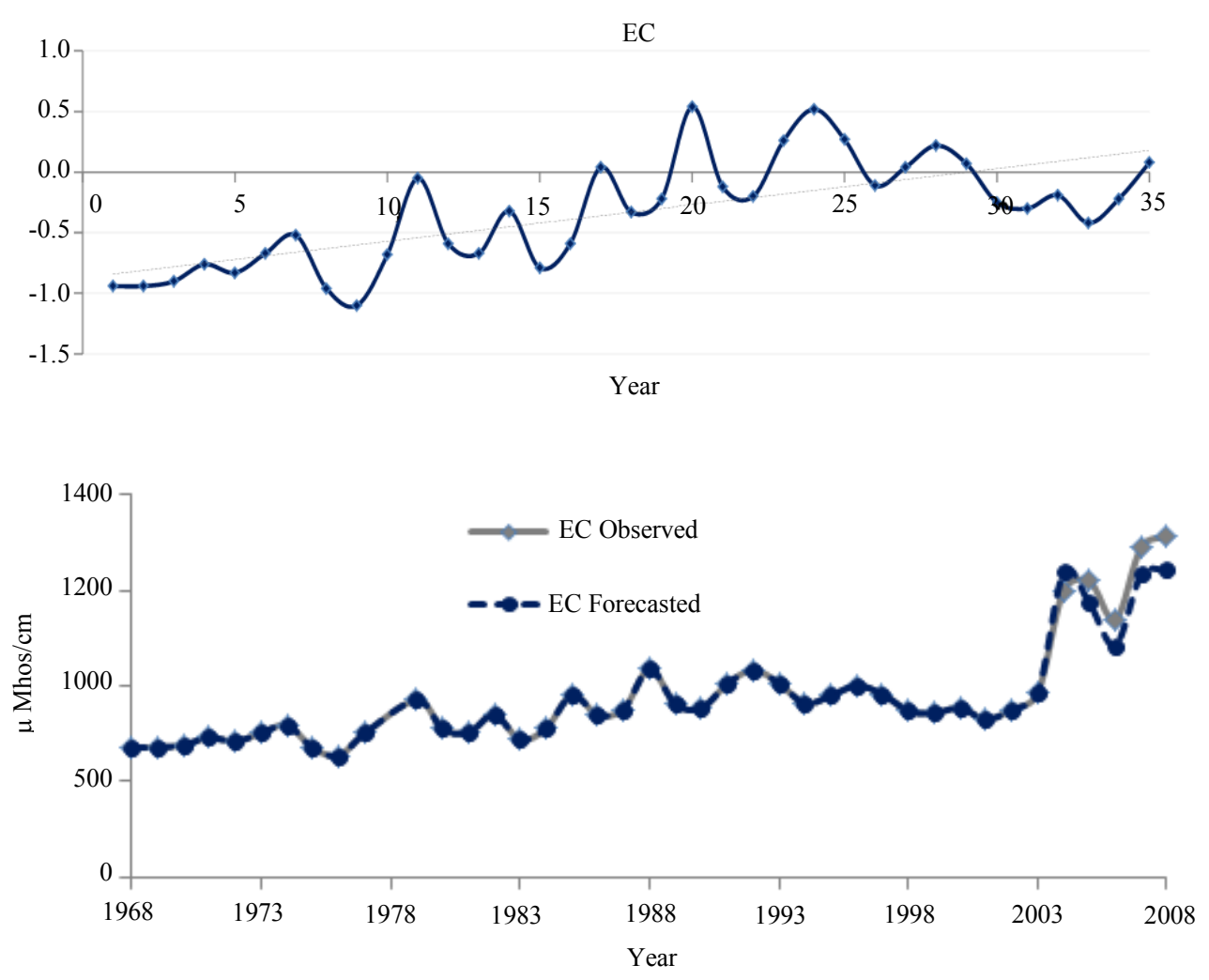

Fig. 3: Standardized time series of EC and the forecasted values for 5 years 

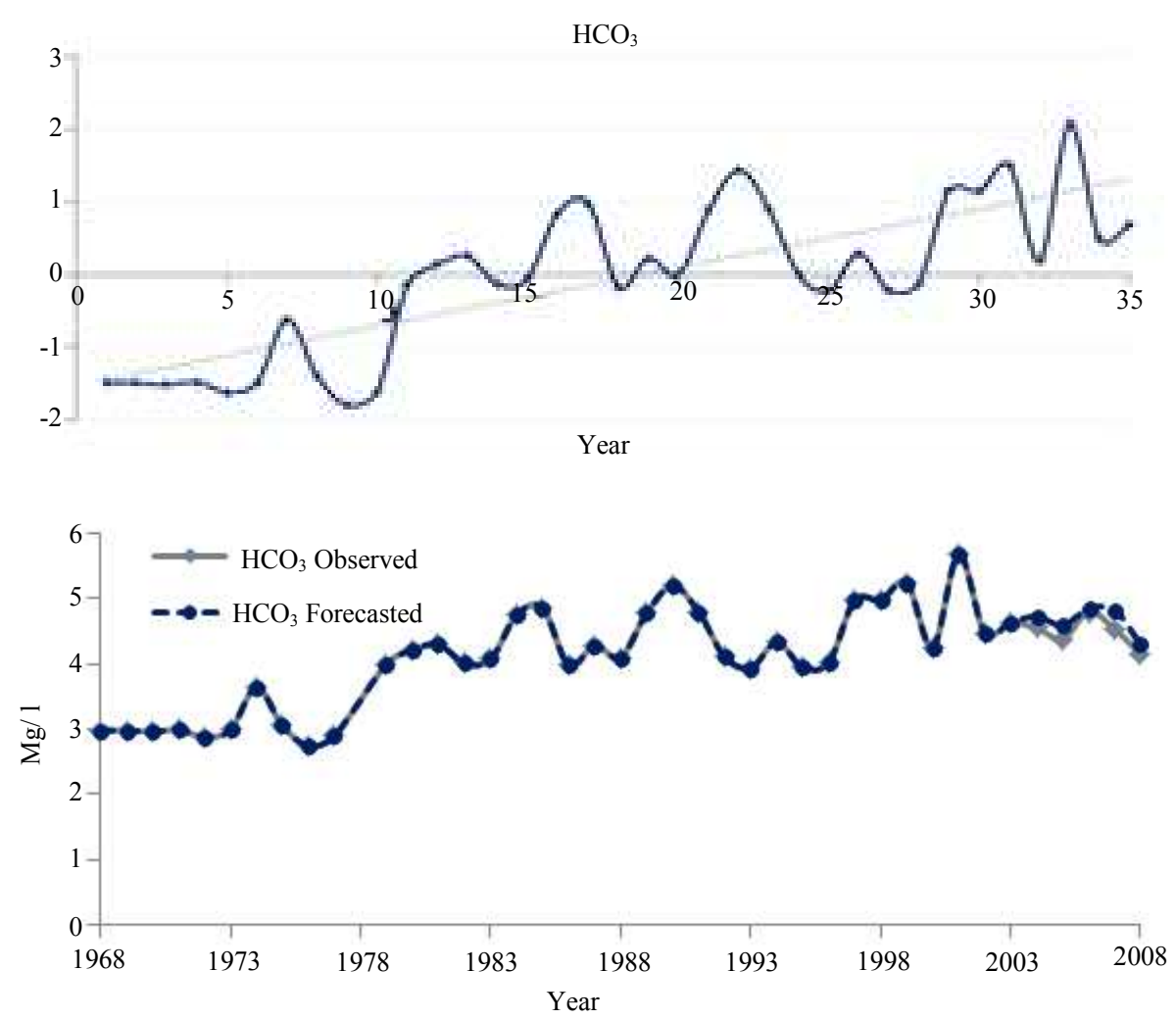

Fig. 4: Standardized time series of $\mathrm{HCO}_{3}{ }^{-}$and the forecasted values for 5 years
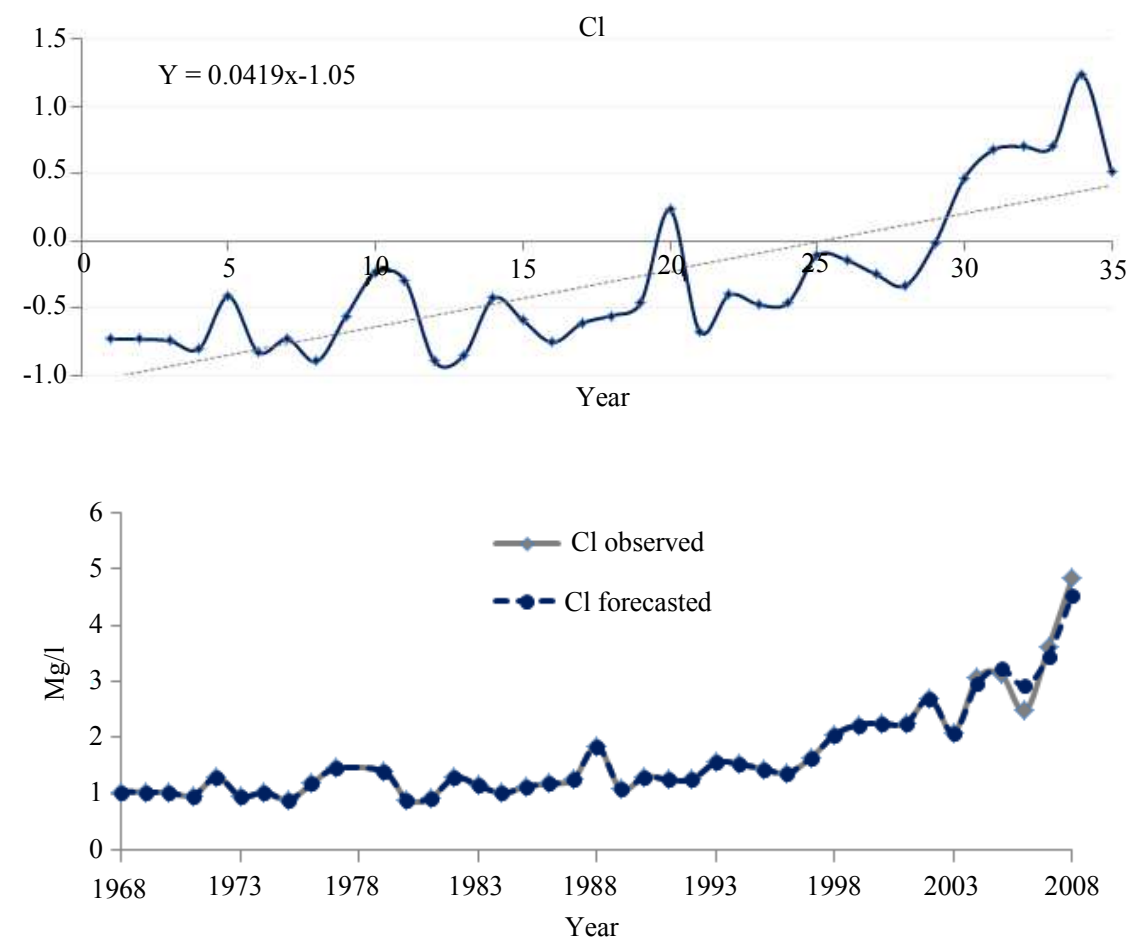

Fig. 5: Standardized time series of $\mathrm{Cl}^{-}$and the forecasted values for 5 years 
$\mathrm{SO}_{4}$
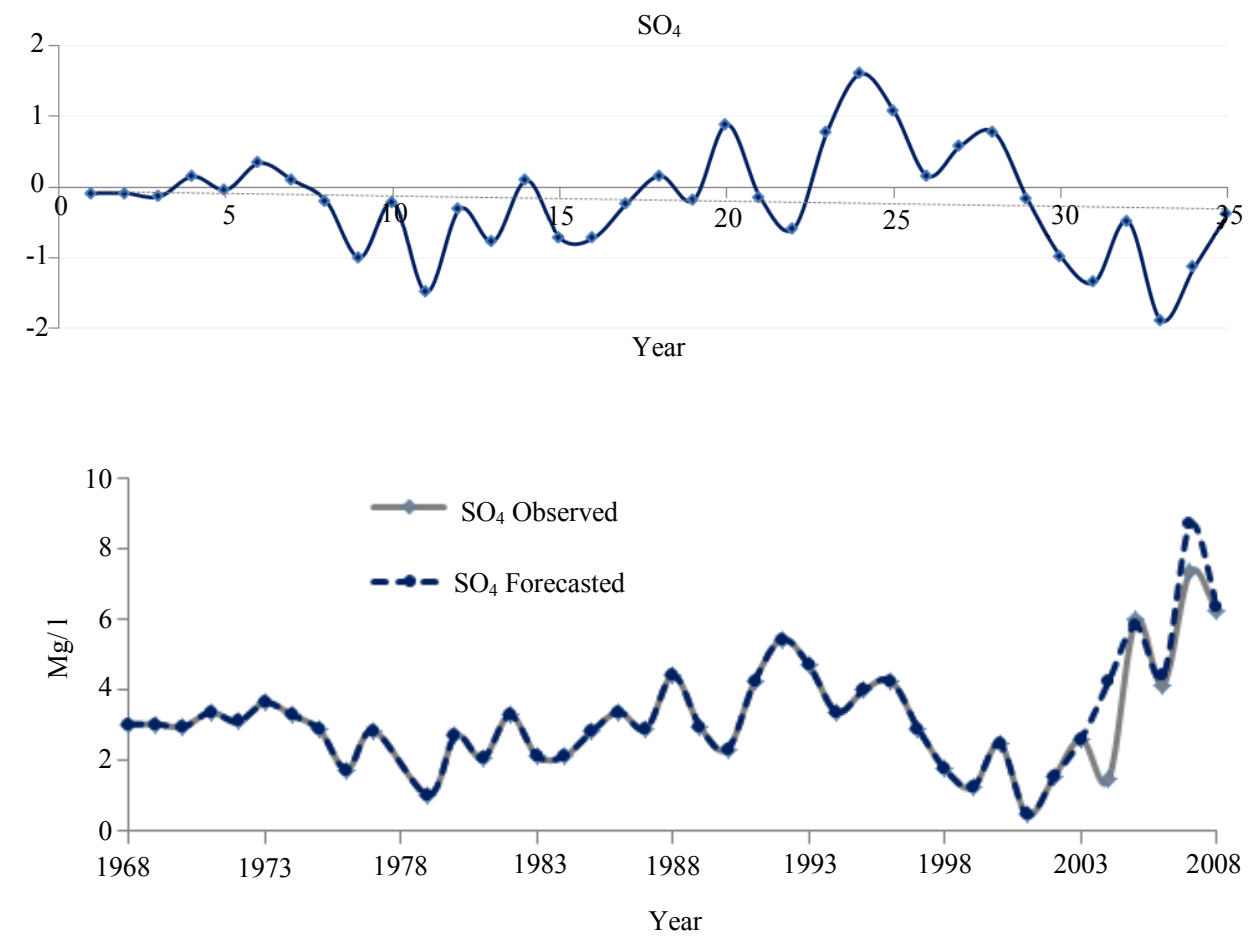

Fig. 6: Standardized time series of $\mathrm{SO}_{4}{ }^{2-}$ and the forecasted values for 5 years
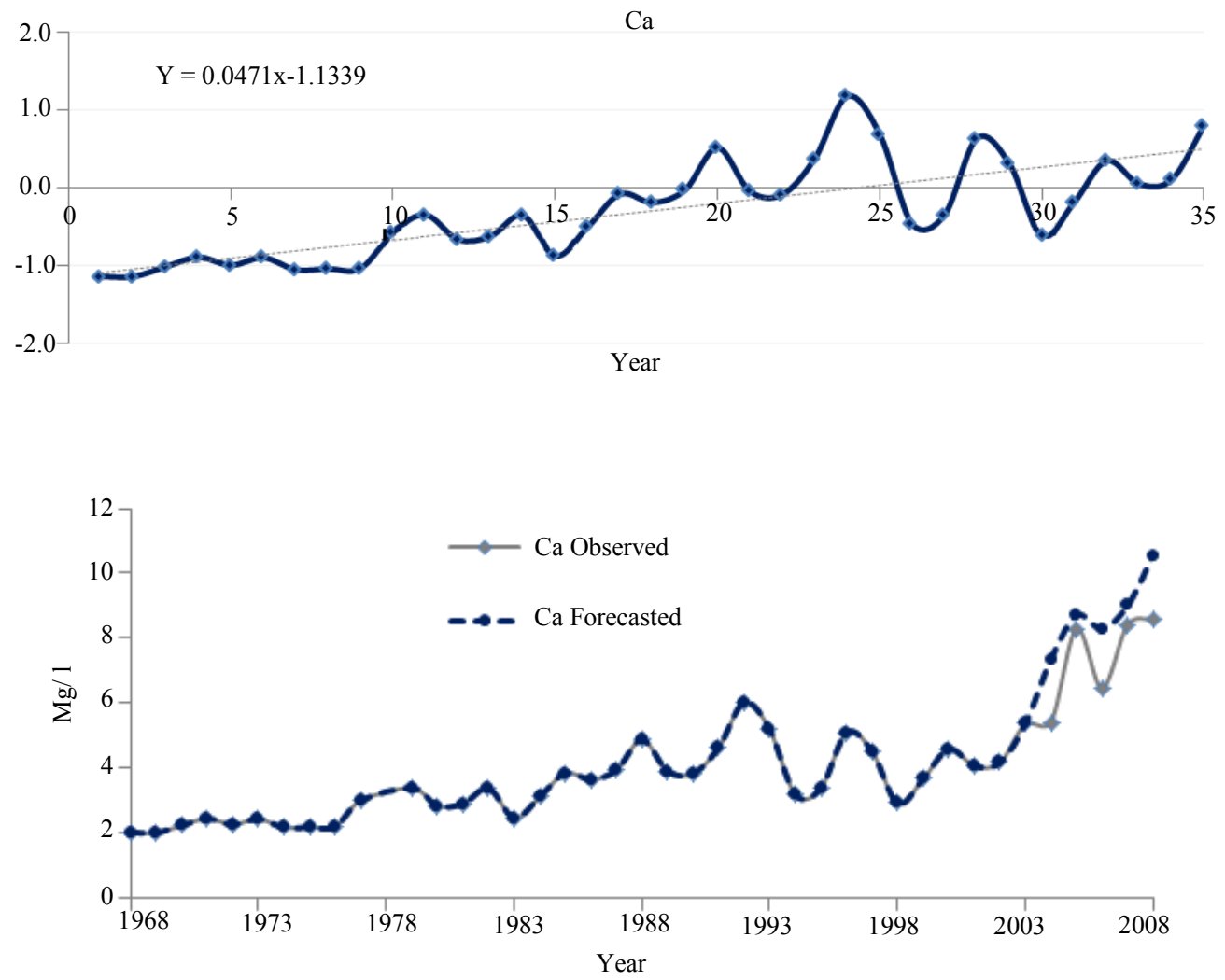

Fig. 7: Standardized time series of $\mathrm{Ca}^{2+}$ and the forecasted values for 5 years 

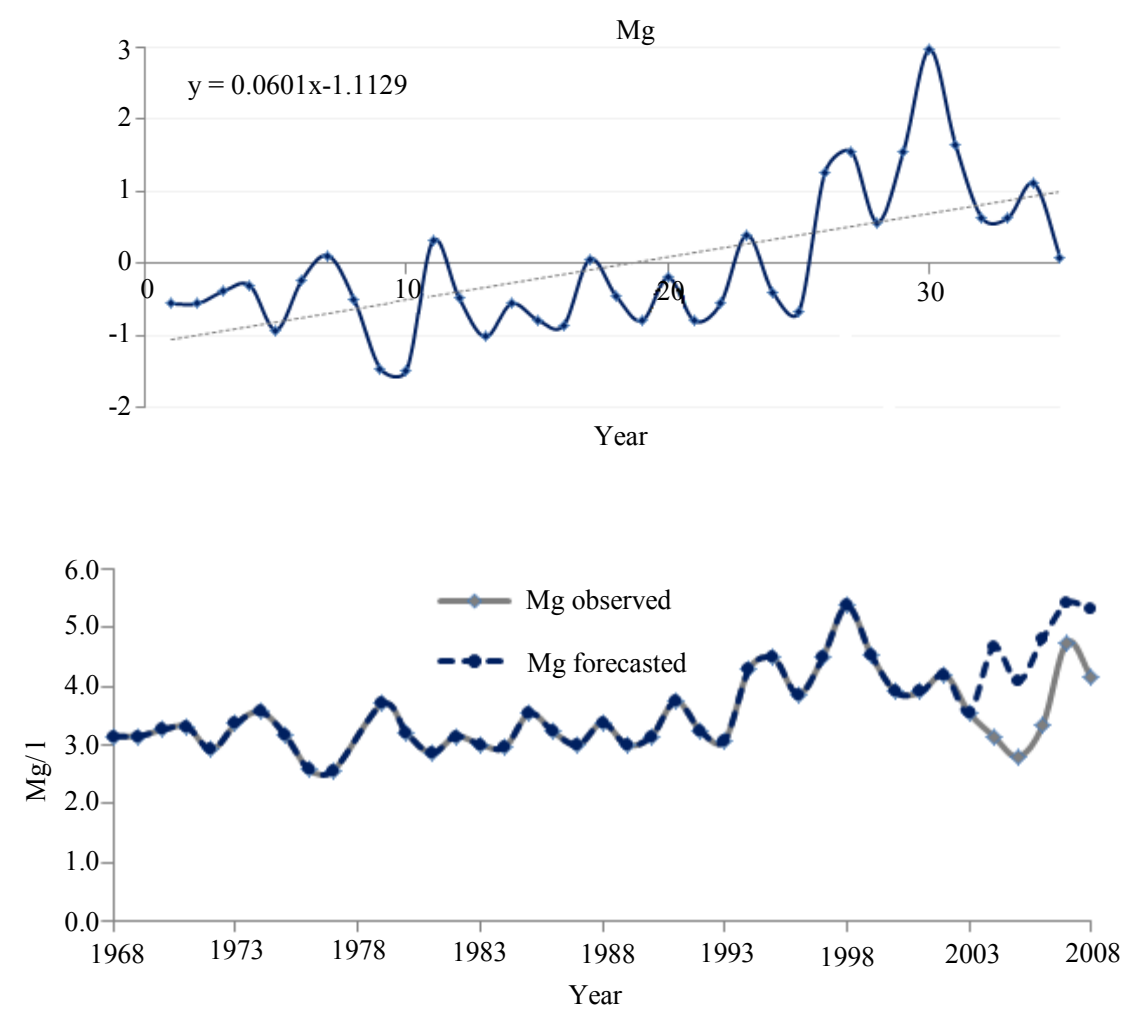

Fig. 8: Standardized time series of $\mathrm{Mg}^{2+}$ and the forecasted values for 5 years
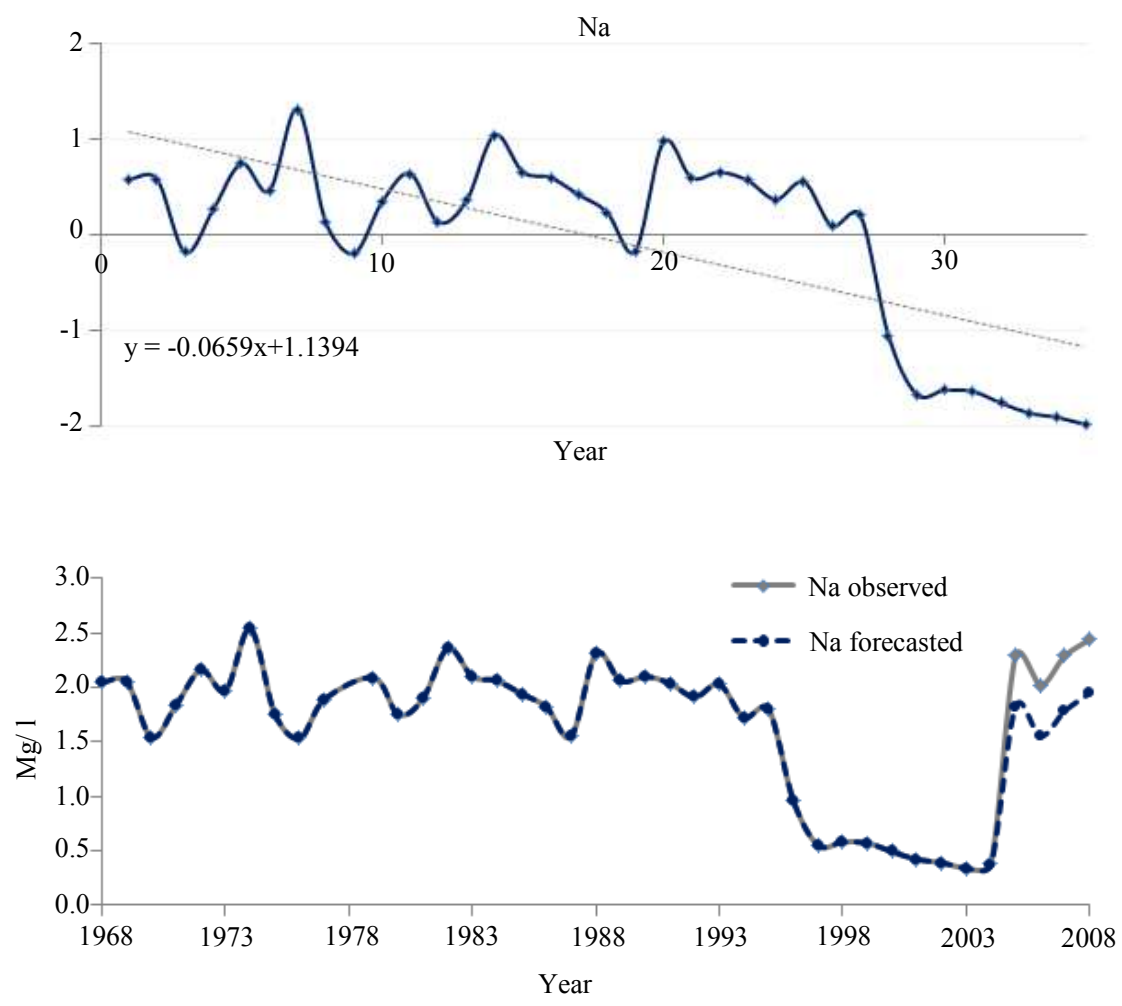

Fig. 9: Standardized time series of $\mathrm{Na}^{+}$and the forecasted values for 5 years 

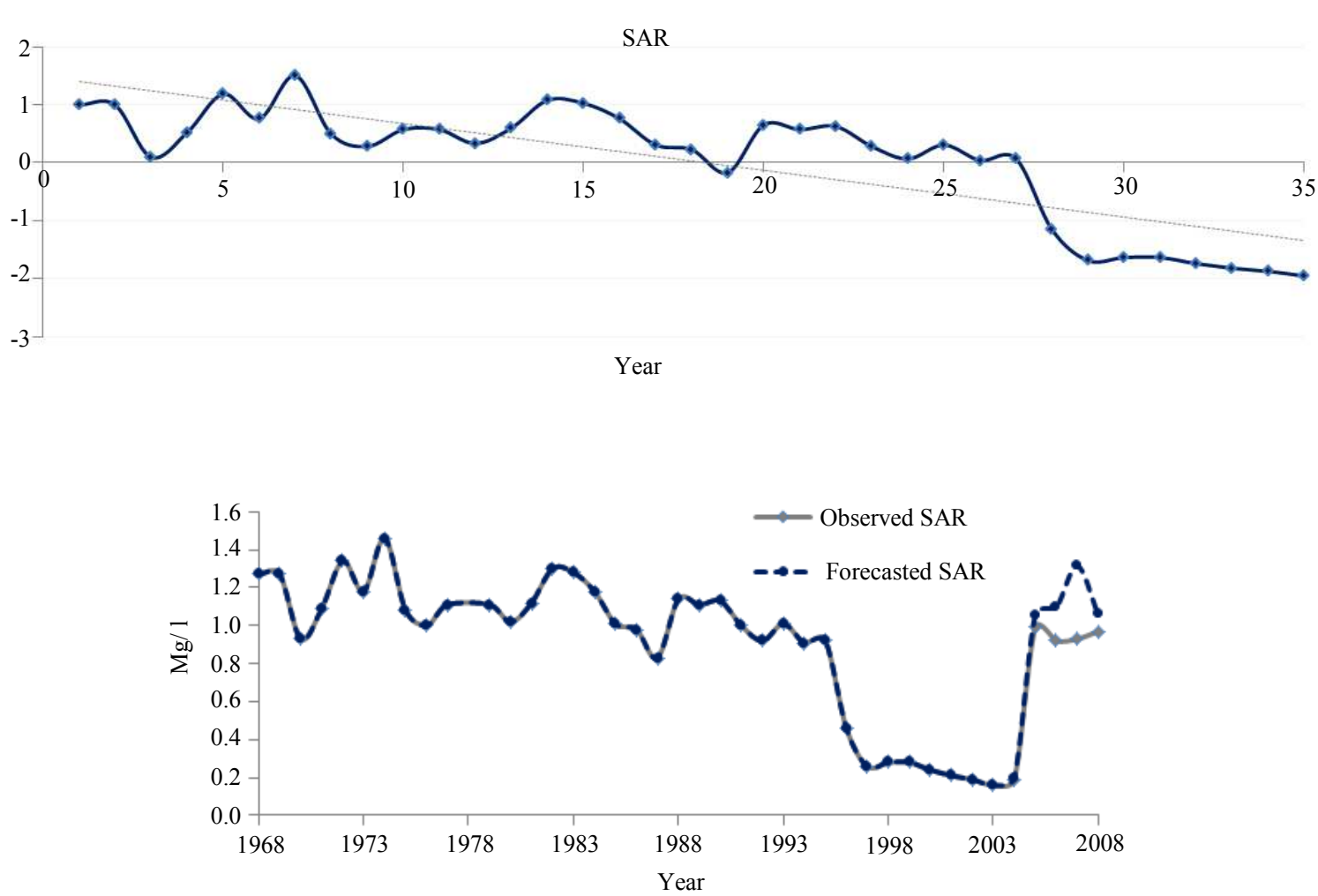

Fig. 10: Standardized time series of SAR and the forecasted values for 5 years

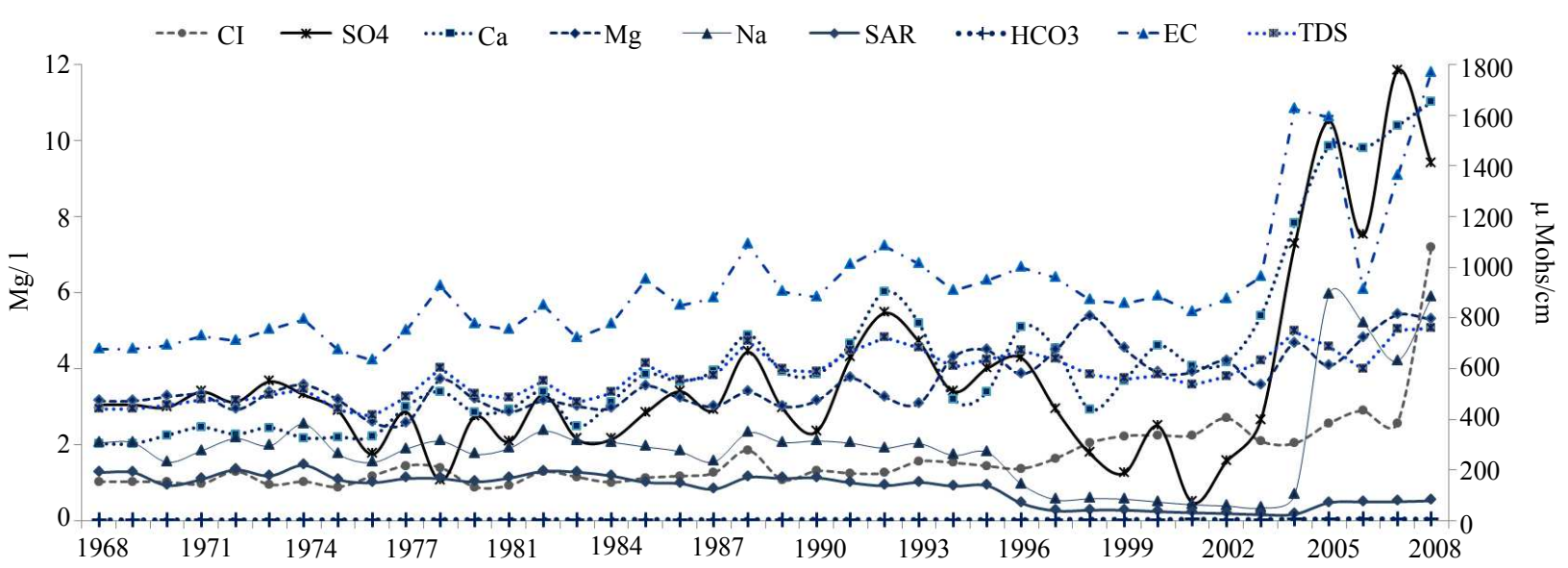

Fig. 11: Time series of forecasted values for the last 5 years of water quality parameters

Figure 9 shows standard series of $\mathrm{Na}^{+}$. The Figure shows that series follow a decreasing trend. Modeling was done for $\mathrm{Na}^{+}$series after trend elimination which is presented in this Figure as well.

The results show that the selected model, shown in Table 8, is capable of modeling the series well.

Finally, Fig. 10 demonstrates standard series of SAR. Modeling the SAR series was done after trend elimination which is presented in this Figure as well.
Table 9 shows that the selected model is capable of modeling the series well.

\section{The Results of Forecasting}

Table 10 shows the results of forecasting for 9 parameters. Also time series of $\mathrm{HCO}^{3-}, \mathrm{Cl}^{-}, \mathrm{SO}_{4}{ }^{2+}, \mathrm{Ca}^{+}$, $\mathrm{Mg}^{2+}, \mathrm{Na}^{+}, \mathrm{SAR}$, TDS and EC are shown in Fig. 11. The last 5 years of time series demonstrate the forecasted values for parameters. 
Table 7: The results of $\mathrm{Mg}^{2+}$ generation, order $(1,1)$

\begin{tabular}{llllll}
\hline MODEL & R & $\mathrm{R}^{2}$ & AIC & RMSE & VE \% \\
\hline$(1,0,1)$ & 0.72 & 0.51 & -19.21 & 0.11 & 1.02 \\
$(1,1,1)$ & 0.69 & 0.48 & -19.63 & 0.11 & 1.03 \\
$(1,0,2)$ & 0.73 & 0.53 & -22.28 & 0.10 & 1.05 \\
$(2,0,1)$ & 0.67 & 0.45 & -16.90 & 0.12 & 1.12 \\
$(2,0,2)$ & 0.80 & 0.64 & -29.81 & 0.09 & 0.84 \\
$(1,1,2)$ & 0.79 & 0.62 & -27.97 & 0.10 & 0.84 \\
$(2,1,1)$ & 0.80 & 0.65 & -29.72 & 0.09 & 0.94 \\
$(2,1,2)$ & 0.80 & 0.65 & -27.76 & 0.10 & 0.95 \\
\hline
\end{tabular}

Table 8: The results of $\mathrm{Na}^{+}$generation, order $(1,2)$

\begin{tabular}{llllll}
\hline MODEL & $\mathrm{R}$ & $\mathrm{R}^{2}$ & AIC & RMSE & VE \% \\
\hline$(1,0,1)$ & 0.87 & 0.75 & -47.43 & 0.08 & 1.06 \\
$(1,1,1)$ & 0.87 & 0.75 & -46.73 & 0.08 & 0.93 \\
$(1,0,2)$ & 0.87 & 0.75 & -45.56 & 0.08 & 1.07 \\
$(2,0,1)$ & $\ldots$ & & & & \\
$(2,0,2)$ & 0.89 & 0.80 & -50.54 & 0.07 & 0.95 \\
$(1,1,2)$ & 0.89 & 0.78 & -49.33 & 0.07 & 0.91 \\
$(2,1,1)$ & 0.87 & 0.76 & -45.04 & 0.08 & 0.94 \\
$(2,1,2)$ & 0.89 & 0.78 & -47.42 & 0.07 & 0.91 \\
\hline
\end{tabular}

Table 9: The results of SAR generation, order $(1,2)$

\begin{tabular}{llllll}
\hline MODEL & R & $\mathrm{R}^{2}$ & AIC & RMSE & VE \% \\
\hline$(1,0,1)$ & $\ldots$ & & & & \\
$(1,1,1)$ & 0.91 & 0.83 & -56.16 & 0.07 & 0.83 \\
$(1,0,2)$ & 0.90 & 0.82 & -52.50 & 0.07 & 1.03 \\
$(2,0,1)$ & $\ldots$ & & & & \\
$(2,0,2)$ & $\ldots$ & & & & \\
$(1,1,2)$ & 0.91 & 0.83 & -54.13 & 0.07 & 0.81 \\
\hline
\end{tabular}

Table 10: Results of forecasting the 5 years of parameters

\begin{tabular}{llll}
\hline Parameter & RMSE & VE \% & $\mathrm{R}^{2}$ \\
\hline TDS & 40.91 & 0.07 & 0.79 \\
$\mathrm{EC}$ & 60.33 & 0.08 & 0.65 \\
$\mathrm{HCO}_{3}{ }^{-}$ & 0.09 & 0.04 & 0.86 \\
$\mathrm{Cl}^{-}$ & 0.12 & 0.07 & 0.95 \\
$\mathrm{SO}_{4}{ }^{2-}$ & 0.62 & 0.44 & 0.73 \\
$\mathrm{Ca}^{2+}$ & 0.68 & 0.20 & 0.70 \\
$\mathrm{Mg}^{2+}$ & 0.56 & 0.26 & 0.88 \\
$\mathrm{Na}^{+}$ & 0.19 & 0.18 & 1.00 \\
$\mathrm{SAR}$ & 0.09 & 0.16 & 0.91 \\
\hline
\end{tabular}

\section{Conclusion}

In this study, nine water quality parameters of Madian Rood River were studied at Baraftab station. The ARIMA modeling process was found suitable in generating and forecasting the parameters. $\mathrm{SO}_{4}{ }^{2-}, \mathrm{Na}^{+}$ and SAR show a decreasing trend in spite of other elements of water quality, which show an increasing trend. However, using one lag to eliminate the trend stationary time series were prepared to work on.

Also investigation of observed time series shows that there is a common increasing trend for all parameters except forSO ${ }_{4}^{2-}, \mathrm{Na}^{+}$and SAR. EC, $\mathrm{Cl}^{-}, \mathrm{Ca}^{2+}, \mathrm{Mg}^{2+}$ and $\mathrm{HCO}_{3}^{-}$show an increasing trend which is a sign for deterioration of water quality in the region.
Based on the field studies (JCE, 2005), the high growth and relative density of population, increasing the consumption of artificial stocks, leaving urban wastewaters and majority of rural sewage in traditional method through rivers, inconvenient methods of burying litters, dispersion of rubbishes and litters in surface waters and streams which finally inflow through rivers are considered as the major reasons of water quality deterioration. Agricultural wastewaters and livestock are other reasons which make surface waters polluted. Also the danger of water quality aggravation is increasing as a result of high population growth in the region and efficient actions are necessary in the region to prevent more environmental destruction.

\section{Acknowledgement}

We thanks Water Resources Engineering Department, Faculty of Agriculture, Bu-Ali Sina University, Hamedan, 6517833131, Iran.

\section{Author's Contributions}

Maryam Ghashghaie, KavehOstad-Ali-Askari, Vijay P. Singh and Saeid Eslamian designed the study, collected data, wrote the manuscript and revised it.

\section{Ethics}

This study approved by Water Resources Engineering Department, Faculty of Agriculture, Bu-Ali Sina University, Hamedan, 6517833131, Iran.

\section{References}

Ahmad, S., I.H. Khan and B.P. Parida, 2001. Performance of stochastic approaches for forecasting river water quality. Water Res., 35: 4261-4266. DOI: 10.1016/S0043-1354(01)00167-1

Box, G.E.P. and G.M. Jenkins, 1976. Time Series Analysis, Forecasting and Control. 1st Edn., Holden-Day, Toronto.

Chang, T.J., 1988. Stochastic forecast of water losses. J. Irrigat. Drainage Eng., 114: 558-558. DOI: 10.1061/(ASCE)0733-9437(1988)114:3(547)

Chenini, I. and S. Khemiri, 2009. Evaluation of ground water quality using multiple linear regression and structural equation modeling. Int. J. Environ. Sci. Technol., 6: 509-519.

Chow, V.T. and S.J. Kareliotis, 1970. Analysis of stochastic hydrologic systems. Water Resources Res., 16: 1569-1582. DOI: 10.1029/WR006i006p01569

Damle, C. and A. Yalcin, 2007. Flood prediction using time series data mining. J. Hydrol., 333: 305-316. DOI: 10.1016/j.jhydrol.2006.09.001 
Durdu, Ö.F., 2010. Stochastic approaches for time series forecasting of boron: A case study of Western Turkey. Environ. Monitor. Assessment, 169: 687-701. DOI: 10.1007/s10661-009-1208-y

El-Shaarawi, A.H., S.R. Esterby and K.W. Kuntz, 1983. A statistical evaluation of trends in the water quality of the Niagara River. J. Great Lakes Res., 9: 234-240. DOI: 10.1016/S0380-1330(83)71892-7

Fang, H., X. Wang, L. Lou, Z. Zhou and J. Wu, 2010. Spatial variation and source apportionment of water pollution in Qiantang River (China) using statistical techniques. Water Res., 44: 1562-1572.

DOI: $10.1016 /$ j.watres.2009.11.003

Faruk, D.Ö., 2010. A hybrid neural network and ARIMA model for water quality time series prediction. Eng. Applic. Artificial Intell., 23: 586-594.

DOI: 10.1016/j.engappai.2009.09.015

Gangyan, Z., N.K. Goel and V.K. Bhatt, 2002. Stochastic modelling of the sediment load of the upper Yangtze River (China). Hydrol. Sci. J., 47: S93-S105. DOI: 10.1080/02626660209493025

Ghashghaie, M. and H. Nozari, 2018. Determining the effect of dam construction on Urmia lake water level- A time series method. JAST.

Hanh, P.T.M., N.V. Anh, D.T. Ba, S. Sthiannopkao and K.W. Kim, 2010. Analysis of variation and relation of climate, hydrology and water quality in the lower Mekong River. Water Sci. Technol., 62: 1587-1594. DOI: $10.2166 /$ wst.2010.449

Hirsch, R.M., J.R. Slack and R.A. Smith, 1982. Techniques of Trend analysis for monthly water quality data. Water Resources Res., 18: 107-121. DOI: 10.1029/WR018i001p00107

Irvine, K.N., J.E. Richey, G.W. Holtgrieve, J. Sarkkula and M. Sampson, 2011. Spatial and temporal variability of turbidity, dissolved oxygen, conductivity, temperature and fluorescence in the lower Mekong River-Tonle Sap system identified using continuous monitoring. Int. J. River Basin Manage., 9: 151-168.

DOI: $10.1080 / 15715124.2011 .621430$.

Jalal Kamali, N., 2006. Forecasting the variations of inflow to Jiroft Dam using time series theories. Proceedings of the 6th International Seminar on River Engineering, (SRE' 06), Shahid Chamran University, Ahvaz, Iran.

JCE, 2005. Integrated program of adaptation to climate study. Jamab Consulting Engineers, Karkhe Watershed.

Jassby, A.D., J.E., Reuter and C.R. Goldman, 2003. Determining long-term water quality change in the presence of climate variability: Lake Tahoe (U.S.A.). Canadian J. Fisheries Aquatic Sci., 60: 1452-1461. DOI: 10.1139/f03-127

Karamouz, M. and S.H. Araghinejad, 2015. Advanced hydrology. Amir Kabir University of Technology (Poly Technics), Tehran, Iran.
Khalil Arya, F. and L. Zhang, 2015. Time series analysis of water quality parameters at Stillaguamish River using order series method. Stochastic Environ. Res. Risk Assessment, 29: 227-239. DOI: $10.1007 / \mathrm{S} 00477-014-0907-2$

Kim, J.H., J. Lee, T.J. Cheong, R.H. Kim and D.C. Koh, et al., 2005. Use of time series analysis for the identification of tidal effect on groundwater in the coastal area of Kimje, Korea. J. Hydrol., 300: 188-198. DOI: 10.1016/j.jhydrol.2004.06.004

Komornık, J.M., R. Komornıkova, D. Mesiar, J. Szokeova and. J. Szolgay, 2006. Comparison of forecasting performance of nonlinear models of hydrological time series. Phys. Chem. Earth, Parts $\mathrm{A} / \mathrm{B} / \mathrm{C}, 31: 1127-1145$.

DOI: $10.1016 /$ j.pce.2006.05.006

Kurunç, A., K. Yürekli and O. Çevik, 2005. Performance of two stochastic approaches for forecasting water quality and streamflow data from Yeşilırmak River, Turkey. Environ. Model. Software, 20: 1195-1200. DOI: 10.1016/j.envsoft.2004.11.001

Lee, J. and K. Lee, 2003. Viability of natural attenuation in a petroleum-contaminated shallow sandy aquifer. Environ. Pollu., 126: 201-212. DOI: 10.1016/S0269-7491(03)00187-8

Lehmann, A. and M. Rode, 2001. Long-term behaviour and cross-correlation water quality analysis of the river Elbe, Germany. Water Res., 35: 2153-2160. DOI: 10.1016/S0043-1354(00)00488-7

Loftis, J.C., 1996. Trends in groundwater quality. Hydrol. Processes, 10: 335-355.

DOI:

$10.1002 /($ SICI $) 1099$ 1085(199602)10:2<335::AID-HYP359>3.0.CO;2-T

McKerchar, A.I. and L.W. Delleur, 1974. Application of seasonal parametric linear stochastic models to monthly flow data. J. Water Resource Res., 10: 246-255. DOI: 10.1029/WR010i002p00246

Panda, D.K., A. Kumar and S. Mohanty, 2011. Recent trends in sediment load of the tropical (Peninsular) river basins of India. Global Planetary Change, 75: 108-118. DOI: 10.1016/j.gloplacha.2010.10.012

Pankratz, A., 1983. Forecasting with Univariate Box-Jenkins Models: Concepts and Cases. 1st Edn., John Wiley AND Sons, New York.

Parmar, K.S. and R. Bhardwaj, 2014. Water quality management using statistical analysis and timeseries prediction model. Applied Water Sci., 4: 425-434. DOI: 10.1007/s13201-014-0159-9.

Prasad, B., P. Kumari, S. Bano and S. Kumari, 2014. Ground water quality evaluation near mining area and development of heavy metal pollution index. Applied Water Sci., 4: 11-17. DOI: $10.1007 / \mathrm{s} 13201-013-0126-\mathrm{x}$ 
Robson, A.J. and C. Neal., 1996. Water quality trends at an upland site in Wales, UK, 1983-1993. Hydrol. Processes, 10: 183-203. DOI: 10.1002/(SICI)10991085(199602)10:2<183::AID-HYP356>3.0.CO;2-8

Salas, J.D., J.W. Delleure, V.D. Yevjevich and W.L. Lane, 1980. Applied modeling of hydrologic time series. Water Resources Publications, Littleton, CO.

Seth, R., P. Singh, M. Mohan, R. Singh and R.S. Aswal, 2013. Monitoring of phenolic compounds and surfactants in water of Ganga Canal, Haridwar (India). Applied Water Sci., 3: 717-720. DOI: $10.1007 / \mathrm{s} 13201-013-0116-\mathrm{Z}$

Singh, K.P., A. Malik, D. Mohan and S. Sinha, 2004. Multivariate statistical techniques for the evaluation of spatial and temporal variations in water quality of Gomti River (India)--a case study. Water Res., 38: 3980-3992. DOI: 10.1016/j.watres.2004.06.011

Sheng, H. and Y.Q. Chen, 2011. FARIMA with stable innovations model of Great Salt Lake elevation time series. Signal Process., 91: 553-561.

DOI: $10.1016 /$ j.sigpro.2010.01.023

Stansfield, B., 2001. Effects of sampling frequency and laboratory detection limits on the determination of time series water quality trends. New Zealand J. Marine Freshwater Res., 35: 1071-1075.

DOI: $10.1080 / 00288330.2001 .9517064$
Su, S., D. Li, Q. Zhang, R. Xiao and F. Huang, et al., 2011. Temporal trend and source apportionment of water pollution in different functional zones of Qiantang River, China. Water Res., 45: 1781-1795. DOI: $10.1016 /$ j.watres.2010.11.030

Thomas, H.A. and M.B. Fiering, 1962. Mathematical Synthesis of Stream Flow Sequences for the Analysis of River Basin by Simulation. 1st Edn., Harward University Press, Cambridge, pp: 751.

Tsakiris, G. and D. Alexakis, 2012. Water quality models: An overview. European Water, 37: 33-46.

Vandaele, W., 1983. Applied Time Series and BoxJenkins Models. 1st Edn., Academic Press, Inc., New York.

Wilson, T.M. and A.E. Ogden and H.H. Mills, 1992. Time-Series analysis of groundwater chemistry in the west Tennessee sand aquifers.

$\mathrm{Yu}$, Y.S., S.C. Zou and D.Whittemore, 1993. Nonparametric trend analysis of water quality data of rivers in Kansas. J. Hydrol., 150: 61-80.

DOI: 10.1016/0022-1694(93)90156-4 